\title{
Nature Neuroscience turns 10
}

\author{
The first issue of Nature Neuroscience appeared a decade ago. We look back on the history of the journal and the field.
}

$\mathbf{T}$ en years ago this month, the Nature Neuroscience editors were obsessed with one question: How many manuscripts would be ready for the first issue? Asking the referees to return their reviews quickly had produced enough acceptable papers, but far too many authors had gotten the news at the last minute; only six papers were available for copy editing a week before the issue deadline.

Founding editor Charles Jennings knew how to handle this sort of problem. Picking up the phone, he called each of the corresponding authors in turn. "We're finalizing the contents of our inaugural issue, and I might be able to fit in your paper," he told them, "but only if you can return the revised version by tomorrow." To the amazement of his junior editors, every author agreed and delivered the manuscript as promised. With 13 primary research papers, the first issue turned out to be far better than its editors had initially feared. Indeed, it included what is now one of the journal's ten most-cited papers of all time ${ }^{1}$.

Those anxious weeks feel very far in the past. Since its launch, the journal has received almost 25,000 manuscript submissions and published just under 2,000 papers. The editorial staff has doubled from three to six editors. With an acceptance rate of less than $8 \%$ and submission numbers continuing to increase every year, the journal has become an integral part of the neuroscience field.

A journal cannot be any better than the quality of its best submissions, however, which in turn is determined by its reputation. The effectiveness of its peer review process is one key determinant of that reputation, along with how well the journal is perceived to serve the needs of the community. Over the years, the Nature journals have adopted various policies to meet these needs, from publishing competing financial interests statements to asking authors to sign a license to publish rather than transferring their copyright to the journal. We have added new article types, including Technical Reports for methods papers and Resources for publication of large datasets of broad significance to the community. Most recently, Nature Neuroscience joined the neuroscience peer review consortium to reduce the workload of referees by allowing their reviews to be used at multiple journals.

The editors have also worked to serve the community by enhancing the journal's web resources, starting with its launch as the first Nature journal with full online content-a lifetime ago in internet years. The journal blog, Action Potential (http://blogs.nature.com/nn/ actionpotential), has attracted a substantial readership, receiving as many hits as the journal's homepage each month. Many readers seem reluctant to post comments, but that is unfortunately common to all online forums that ask scientists to sign their names to their remarks. We hope that neuroscientists will become more comfortable with making such informal discussions available to all interested parties as time goes on and are working toward expanding readers' ability to comment on all of the work that is published in the journal. Nature Neuroscience has also supported the Neuroscience Gateway (http://www.neurosciencegateway.org/index.shtml), which provides biweekly summaries of the most exciting research and a library of neuroscience papers published in top journals, along with neuroscience news.

To mark this anniversary, Action Potential lists the top papers for each year of the journal's history through 2005, along with the ten most-cited papers of the decade (http://blogs.nature.com/nn/actionpotential/2008/04/ top_papers.html). These papers will be freely available during May.

The most-cited paper, published in December 2000, reports that chronic systemic exposure to the pesticide rotenone, a mitochondrial complex I inhibitor, reproduces multiple features of Parkinson's disease in rats ${ }^{2}$. Close behind it are a pair of papers from March 1999, which show that either learning ${ }^{3}$ or exercise ${ }^{4}$ can increase the survival of newborn neurons in the adult brain. This list is biased, of course, toward older papers, which have had more time to collect citations. Thus, it is notable that the twelfth most-cited paper of the decade was published in August 2004, more than three and a half years later than any of the top ten papers. This paper ${ }^{5}$ reports that the mothering style of rats alters their offspring's epigenome at a glucocorticoid receptor-gene promoter in the hippocampus. Furthermore, a histone deacetylase inhibitor reverses these biochemical changes in adulthood and reduces the offspring's hormonal responsiveness to stress.

This work exemplifies the increasingly interdisciplinary nature of neuroscience. Early on, it was straightforward to assign any paper as being molecular, cellular, systems or cognitive. Recently, with researchers determining the cognitive effects of gene alleles or the cellular basis of functional imaging, it has become difficult to distinguish one field from another. We welcome this increase in interdisciplinary approaches and continue to encourage submissions from all areas of neuroscience.

A major strength of Nature Neuroscience has been the continuity provided by its veteran editors. Thus, we are pleased to announce that the third chief editor of the journal, beginning with the next issue, will be Kalyani Narasimhan, who started her editorial career with the journal's launch. Nature Neuroscience will remain in steady and experienced hands.

The current chief editor, Sandra Aamodt, is leaving the journal to pursue two avocations: science writing and sailing. She recently published her first book, Welcome to Your Brain, and will spend the next year and a half writing about the brain for nonscientists from her boat in the South Pacific islands and New Zealand. Through her writing, she hopes to remain engaged with the global neuroscience community.

1. Lupien, S.J. et al. Nat. Neurosci. 1, 69-73 (1998).

2. Betarbet, R. et al. Nat. Neurosci. 3, 1301-1306 (2000).

3. Gould, E., Beylin, A., Tanapat, P., Reeves, A. \& Shors, T.J. Nat. Neurosci. 2, 260-265 (1999).

4. van Praag, H., Kempermann, G. \& Gage, F.H. Nat. Neurosci. 2, 266-270 (1999)

5. Weaver, I.C.G. et al. Nat. Neurosci. 7, 847-854 (2004). 